\title{
Unequal Area Facility Layout Problem Design Based on Mixed Integer Programming
}

\author{
Randa Adi Saputra, Komarudin, and Billy Muhamad Iqbal
}

\begin{abstract}
Facility layout problem, especially with the unequal departmental area (UAFLP), is one of the problems studied in combinatorial optimization and has received the attention of many researchers in the past decade. The research used commonly known problems as a standard problem in facility layout problems. There are some problems that have not found the optimal solution and require a long computation time. This research will develop a mathematical model using Mixed Integer Programming method based on Flexible Bay Structure, one of the common representation models used in UAFLP. This method will meet the constraints that arise throughout the process of forming the result. The goal is to reduce non-feasible solutions to reduce the complexity of possible solutions. Some additional constraint functions will be attempted to be added to the model. Testing is done by comparing the effect of each additional constraint function that has different approaches in cutting the complexity of possible solutions. The comparison result of the combination of the constraint function used indicates which constraint function has a major influence in reducing the computation time of the model. Most of the results of this study approached the best-known results.
\end{abstract}

Index Terms-Flexible bay structure, mixed integer programming, unequal area facility layout problem.

\section{INTRODUCTION}

Facility layout design has a close reinforcement to the size of the physical arrangement of elements in a manufacturing and service system. The purpose of the facility layout design is the design with the minimum material handling cost. With proper facility layout, material handling costs can be reduced. In general, material handling contributes about $20-50$ percent of the total. Reduction in the company's operational costs, along with the increased efficiency of the production system becomes a necessity that every industry needs to do.

The first layout problem is formulated as a Quadratic Assignment Problem (QAP) [1]. Several studies on facility layout issues have been conducted in the last few decades. Nearly 140 of the Facility Layout Problem (FLP) articles have been published in the 20 years prior to 2006 described in the research report [8].

The problem of facilities layout that is often the researcher's attention is Unequal Area Facility Layout Problem (UAFLP). UAFLP is one type of problem in facility layout with unequal wide constraints. The goal of UAFLP is to allocate departments into a facility to obtain the most efficient arrangement. Each department has a different size

Manuscript received September 23, 2017; revised December 12, 2017.

The authors are with the Industrial Engineering Department, Faculty of Engineering, Universitas Indonesia, Depok, Indonesia (e-amil: randa.adi@ui.ac.id). and area, but has a maximum ratio of the length and width to each department (Maximum Aspect Ratio). The UAFLP study has a final objective to minimize the total cost of material handling between departments.

The Flexible Bay Structure (FBS) model has recently gained much attention from several researchers. This model was first defined by Tong (1991) in his research to develop techniques for layout design. In the FBS completion formula, the laying of department locations within the facility produces several columns. Most FBS models deliver the best results for UAFLP issues [9].

The larger the number of departments there are, the search time needed to find a solution to the solution tends to increase. This research will develop a mathematical model that meets the existing constraints with faster search time. Through this mathematical model, it is expected that the resulting solution is better and at least can match the results of the best-known FBS. In the development of the mathematical model, this research will use Mixed Integer Programming (MIP) method.

\section{LITERATURE REVIEW}

Facility Layout Problems are an optimization problem that allocates specific departments within a known dimensional facility. The purpose of the facility layout design is to find the facility design with the cost associated with the minimum interaction among departments.

When all departments have the same area, it becomes easier to determine the number of potential positions that these departments can generate within a facility. When departments have unequal areas, they cannot simply be placed at some central point of a facility. Each department is known to have only a certain area and does not have a fixed length and width. This presents a major difficulty that can arise in the number of possible layouts that these departments can produce.

Initially, UAFLP was developed by Armor and Buffa (1963). They explain that there is a rectangular facility with a fixed Width and Height and several (n) departments that need to be allocated to the facility. Each department has its own wide scale but does not yet have a fixed length and width.

Mixed Integer Programming is one part in the realm of mathematical programming where the mathematics program itself represents the system to be modeled. The variables have their own restrictions such as the value of a variable must be an integer or a variable value must be binary ( 0 or 1$)$.

Mixed Integer Programming has properties for computational time that are exponential to the number of variables. The larger the number of variables, then the computational time used to find the optimal solution will increase exponentially. This can be because there is no 
feasible region bounded by the constraint equation or the variable has an unlimited value [16].

\section{Methodology}

There are three major stages in this research which started from data collection, model development, and analysis of the effect of constraints on the mathematical model on the computing time of completion of each problem. The data used are a collection of facility layout problems created by previous researchers and are well known as standard issues in UA-FLP related research.

This study adopted a mathematical model developed by Kulturel-Konak \& Konak (2011) has a purpose function to minimize the total cost of material flow between departments by minimizing the total distance required between departments from the horizontal and the vertical sides.

Set

$\mathrm{n} \in \mathrm{N} \quad$ set of departments

$\mathrm{b} \in \mathrm{B} \quad$ set of maximum number of bays

Parameter

W Width of the facility along the $\mathrm{x}$-axis

$\mathrm{H} \quad$ Length of the facility along the $\mathrm{x}$-axis

$a_{i} \quad$ Area requirement of department i

$\alpha_{i} \quad$ Aspect Ratio of department i

$l_{i}^{\max } \quad$ Maximum permissible side length of department i

$l_{i}^{\min } \quad$ Minimum permissible side length of department i

$f_{i j} \quad$ Amount of material flow between departments i and $\mathrm{j}$

Variabel

$z_{i k} \begin{cases}1 & \text { If department } \mathrm{i} \text { is assigned to bay } \mathrm{k} \\ 0 & \end{cases}$

$r_{i j} \begin{cases}1 & \text { If department } \mathrm{i} \text { is above department } \mathrm{j} \text { in the same } \\ 0 & \end{cases}$ bay

$\delta_{k} \begin{cases}1 & \text { If bay } \mathrm{k} \text { is occupied } \\ 0 & \end{cases}$

$w_{k} \quad$ Width (The length in the $\mathrm{x}$-axis direction)

$l_{i}^{y} \quad$ Height (The length in the y-axis direction)

$h_{i k} \quad$ Height of department $\mathrm{i}$ in bay $\mathrm{k}$

$\left(x_{i}, y_{i}\right)$ Coordinates of the centroid of departments $\mathrm{i}$

$d_{i j}^{x} \quad$ Distance between the centroids of departments $\mathrm{i}$ and $\mathrm{j}$ in the $\mathrm{x}$-axis direction

$d_{i j}^{y} \quad$ Distance between the centroids of departments i and $\mathrm{j}$ in the $\mathrm{y}$-axis direction

\section{Parameter}

$$
\min \sum_{i} \sum_{i<j: f_{i j}>0} f_{i j}\left(d_{i j}^{x}+d_{i j}^{y}\right)
$$

Constraint

The constraints in this study are as follows.
1) Linearize the absolute value term in the rectilinear distance function.

$$
\begin{aligned}
& d_{i j}^{x} \geq x_{i}-x_{j} \\
& d_{i j}^{x} \leq x_{j}-x_{i} \quad \forall i<j \\
& d_{i j}^{y} \geq y_{i}-y_{j} \\
& d_{i j}^{y} \leq y_{j}-y_{i}
\end{aligned}
$$

2) Each department is allocated into one bay.

$$
\sum_{k} z_{i k}=1 \quad \forall i
$$

3) The width of each bay is allocated as the total area of the departments assigned to that divided by length of the facility in the direction of the y-axis.

$$
w_{k}=\frac{1}{H} \sum_{i} z_{i k} a_{i} \quad \forall k
$$

4) Imposes upper and lower bounds on the widths of the bays based on the departments assigned to each bay.

$$
l_{i}^{\min } z_{i k} \leq w_{k} \leq l_{i}^{\max }+W\left(1-z_{i k}\right) \quad \forall i, k
$$

5) Determines the locations of the department centroids along the $\mathrm{x}$-axis.

$$
\begin{aligned}
& x_{i} \geq \sum_{j \leq k} w_{j}-0.5 w_{k}-\left(W-l_{i}^{\mathrm{min}}\right)\left(1-z_{i k}\right) \\
& x_{i} \leq \sum_{j \leq k} w_{j}-0.5 w_{k}+\left(W-l_{i}^{\mathrm{min}}\right)\left(1-z_{i k}\right)
\end{aligned} \quad \forall i, k
$$

6) Determine the length of the department on the y-axis

$$
\frac{h_{i k}}{a_{i}}-\frac{h_{j k}}{a_{j}}-\max \left\{\frac{l^{\max }}{a_{i}}, \frac{l_{j}^{\max }}{a_{j}}\right\}\left(2-z_{i k}-z_{j k}\right) \quad \forall i<j, \forall k
$$

7) The sum of department lengths in the bay corresponds to the length of the bay when the bay is used, or is 0 if the bay is empty.

$$
\sum_{i} h_{i k}=H \delta_{k} \quad \forall k
$$

8) The department height is between the maximum and minimum allowable lengths and when department $i$ is not in bay $\mathrm{k}$ then $h_{i k}$ will be 0 .

$$
l_{i}^{\min } z_{i k} \leq h_{i k} \leq l_{i}^{\max } z_{i k} \quad \forall i, k
$$

9) Calculates department height in $Y$ axis used by other constraints

$$
\sum_{k} h_{i k}=l_{i}^{y} \quad \forall k
$$

10) Determine the position of department in $Y$ axis with top-down relationship of each department in the same bay

$$
y_{i}-0.5 l_{i}^{y} \geq y_{k}+0.5 l_{j}^{y}-H\left(1-r_{i j}\right) \quad \forall i \neq j
$$


11) In the same bay, make sure that department $i$ is above department $\mathrm{j}$ or department $\mathrm{j}$ is above department $\mathrm{i}$.

$$
\begin{array}{ll}
r_{i j}+r_{j i} \leq 1 & \forall i<j \\
r_{i j}+r_{j i} \geq z_{i k}+z_{j k}-1 & \forall i<j, \forall k
\end{array}
$$

12) Ensure the department is within the facility boundary in the $\mathrm{Y}$ axis.

$$
0.5 l_{i}^{y} \leq y_{i} \leq H-0.5 l_{i}^{y} \quad \forall i
$$

13) Forcing the same lower border in $d_{i j}^{y}$ if the department is in the same bay.

$$
d_{i j}^{y} \geq 0.5\left(l_{i}^{\min }+l_{j}^{\min }\right)+H\left(z_{i k}+z_{j k}-2\right) \quad \forall i<j, \forall k
$$

14) Forcing no empty bays between two filled bays.

$$
N \sum_{i}^{\prime} z_{i k} \geq \sum_{i}^{\prime} z_{i, k+1} \quad \forall k<B
$$

15) The distance of the departments in the $X$ axis should be greater than half the sum of the two sides of the department minimum when departments $\mathrm{i}$ and $\mathrm{j}$ are allocated to two different bays.

$$
\begin{array}{ll}
d_{i j}^{x} \geq 0.5\left(l_{i}^{\min }+l_{j}^{\min }\right)+\min \left\{l_{p}^{\min }\right\}(|m-k|-1)+ & \forall i<j \\
B \times W\left(z_{i k}+z_{j m}-2\right) & \forall k \neq m
\end{array}
$$

16) Eliminate the symmetric solution.

$$
\begin{aligned}
& x_{p} \geq \frac{1}{2 W} \sum_{i} a_{i} \\
& y_{p} \geq 0.5 H
\end{aligned}
$$

(1) through (12) are constraints that become the basic model in solving the layout problem of this facility. In some cases, this model can produce an optimal solution. However, if using this model in cases with many departments such as cases with 10 department, the computational time required to solve this problem increases significantly. This is due to the increasing number of departments, the more likely the combination of departmental positions in a facility. Therefore additional constraints are needed that can reduce the possibility of a solution that can be generated. Some constraints are added to the base model to improve model computing performance. [13] to [16] are additional constraints for each problem set and will be seen how they are concerned with the computation time of model completion.

\section{RESULTS AND DISCUSSION}

The model was run by generating the output of the $\mathrm{X}$-axis coordinates and the Y-axis coordinates of each department, department height, bay width, and the allocation of each department into the bay. The main purpose of this study is to see how the effect of adding constraints to computational time required for each problem. Model simulation is done under various conditions.

Here are the model simulation results using the basic model which has 12 constraints. The simulation results provide information on solution value, computation time, and optimality gap.

Solutions generated in the number of departments seven to ten is the optimal solution which has a value of optimality gap of $0 \%$. The greater the number of departments in a facility, the greater the combination of options that can be the layout of a facility. This is what causes when the number of departments gets bigger, and the solution space is also getting bigger, the model's ability in finding the optimal solution becomes less.

TABLE I: MODEL SIMULATION RESUlT WITH (1)-(12)

\begin{tabular}{lllll}
\hline \hline No & Problem Set & Solution & $\begin{array}{c}\text { Computation } \\
\text { Time }(\mathrm{s})\end{array}$ & Optimality Gap \\
\hline 1 & O7 & 120.67 & 32 & $0.00 \%$ \\
2 & FO7 & 23.12 & 27 & $0.00 \%$ \\
3 & FO8 & 22.39 & 104 & $0.00 \%$ \\
4 & O9 & 241.06 & 3500 & $0.00 \%$ \\
5 & V10s & 22899.65 & 6450 & $0.00 \%$ \\
6 & V10a & 21463.06 & 14465 & $0.00 \%$ \\
7 & M11s & 1912.24 & 21220 & $22.40 \%$ \\
8 & M11a & 1504.89 & 86400 & $10.80 \%$ \\
\hline \hline
\end{tabular}

In the problem set V10s and V10a, the number of departments owned on this issue is as large as ten departments. But there is a considerable computation time difference in both problem sets. Both problems have different characteristics where the problem of V10s has minimum side-shape constraints, and problem V10a has constraint aspect ratio shape. Both form constraints affect the lower limit and upper limit of each department to be allocated into a facility. It gives a difference of solution space owned by each problem. Computational time will increase exponentially as the size of the problem gets bigger.

By looking at the simulation results of the model, the greater the number of departments and the complexity of a facility, the time required to find the solution will increase significantly. Therefore, the model needs to be given additional constraints to limit the possibility of solution space so that it can provide faster computation time. The additional constraints to be entered the model are the thirteen constraints to the sixteen constraints Model simulation results by using additional constraints aimed at strengthening the model can be seen in Table II.

Additional constraints have different approaches and characteristics in providing the solution model space constraints. With the addition of [13] to [16] on the facility layout problem solving model, there is a change in solution value and computation time in some problem sets. On departments seven and eight, the value of the resulting solution has not changed and is still optimal. But the increase in the value of the solution occurs on departments nine and ten (O9 and V10s). This condition provides an explanation that the added constraints give effect that can change the model computing time and the value of the solution. In the problem set V10a, by adding [13] to [16], the model provides an optimum fixed value with a much shorter completion time.

For problem sets with more than 11 departments, the time required by the model to find a solution is very long. The author provides a time limit in running models for 24 hours.

Solutions for problems with more than 11 departments are solutions that can be generated before the model is completed by having different optimality gap values. Models that have 
been added [13] to [16] have not been able to provide faster computation time due to the high level of problem complexity.

In the BA12 set problem, the model can yield near optimum value with optimality gap of $1.03 \%$ and computation time is relatively shorter than the problem set with the number of departments more than 11 others. The BA12 has a lower level of complexity. Characteristics of this problem is that can make the model provides a solution value near optimal and computing time is relatively short. The completion time for the problem with the number of departments over eleven is almost entirely up to twenty-four hours.

This study then proceeded to see the effect of each addition of constraints on the computational time required by the model in solving the problem. Each constraint is entered with a different approach. [13] and [15] are constraints with the linear programming approach to the lower limit of the $\mathrm{X}$ axis and the Y axis of each department. [14] is a constraint with the aim of reducing the solution space when there are unfilled bays. [16] is a constraint with the approach of removing a symmetrically visible solution or mirror image with other solutions.

TABLE II: Model Simulation RESUlt WiTH AdDITIONAL (13) - (16)

\begin{tabular}{|c|c|c|c|c|c|c|}
\hline \multirow[b]{2}{*}{ No } & \multirow[b]{2}{*}{$\begin{array}{l}\text { Prob-le } \\
\text { m Set }\end{array}$} & \multicolumn{2}{|c|}{$\begin{array}{c}\text { Model Using } \\
\text { Constraint } 1 \text { - } 12 \\
\end{array}$} & \multicolumn{3}{|c|}{ Model Using Constraint 1 - 16} \\
\hline & & Solution & $\begin{array}{c}\text { Com- } \\
\text { puta-t } \\
\text { ion } \\
\text { Time } \\
\text { (s) }\end{array}$ & Solution & $\begin{array}{c}\text { Comp } \\
\text { utatio } \\
\text { n } \\
\text { Time } \\
(\mathrm{s}) \\
\end{array}$ & $\begin{array}{l}\text { Optima-1 } \\
\text { ity Gap }\end{array}$ \\
\hline 1 & O7 & 120.67 & 32 & 120.67 & 1 & $0.00 \%$ \\
\hline 2 & FO7 & 23.12 & 27 & 23.12 & 1 & $0.00 \%$ \\
\hline 3 & FO8 & 22.39 & 104 & 22.39 & 2 & $0.00 \%$ \\
\hline 4 & O9 & 241.06 & 3500 & 260.92 & 15 & $21.60 \%$ \\
\hline 5 & V10s & 22899.65 & 6450 & 24333.98 & 43 & $18.60 \%$ \\
\hline 6 & V10a & 21463.06 & 14465 & 21463.06 & 51 & $0.00 \%$ \\
\hline 7 & M11s & 1912.24 & 21220 & 1706.55 & 45 & $22.40 \%$ \\
\hline 8 & M11a & 1504.89 & 86400 & 1504.89 & 81 & $10.80 \%$ \\
\hline 9 & M15 & & & 34055.77 & 4711 & $9.56 \%$ \\
\hline 10 & NUG12 & & & 257.5 & 86400 & $38.00 \%$ \\
\hline 11 & NUG15 & & & 527.25 & 86400 & $65.60 \%$ \\
\hline 12 & BA12 & & & 8786 & 2756 & $1.03 \%$ \\
\hline 13 & BA12TS & & & 9176.16 & 86400 & $60.00 \%$ \\
\hline 14 & BA14 & & & 5044.11 & 86400 & $61.70 \%$ \\
\hline 15 & BA14TS & & & 5247.75 & 86400 & $47.60 \%$ \\
\hline
\end{tabular}

The result of adding each constraint on the facility layout completion model shows different results. The value of the solution generated when added to a constraint can be better and vice versa. And changes in computational time tend to have a positive effect with the addition of these constraints.

In the $\mathrm{O} 7$ set problem, computation time tends to increase in performance where before when no additional constraints are added, the time required to find a solution of 32 seconds. All simulation combinations produce an optimum solution. And when constraints are added, the computational time of the entire simulation combination is less than 10 seconds. The best computation time result is obtained by simulation using [14] and combination of all additional constraints, which is 1 second.
In the problem set $\mathrm{FO} 7$, there is a change in solution value when simulated using an additional [14] and [16], and a combination of all additional constraints. The value of the optimum solution was obtained earlier when the model was run without using additional constraints as shown in Table 3. Other optimum values were generated when simulated using a combination of [13] and [15]. This constraint provides strength to the lower-limit model which allows less solution space Optimum. However, the [14] used on this problem provides an unoptimized solution value. This can be due to [14] is a constraint to reduce the solution space where empty bays occur between filled bays. In the simulation with the condition, the department is forced into the facility with the number of bay 2 where the value of the solution is not optimum. The optimum value in FO7 has a bay number of 4 , but due to [14] the department has the least number of bays possible, so its value is not optimal.

In the $\mathrm{O} 9$ set problem, the model has found the optimal solution value when it has not added additional constraints, although it has a long computational time. When simulated by adding special constraints, model simulation results can maintain optimal values only when using constraint 16 . When using other constraints, the results provide an optimum solution value, although it has faster computing time.

TABLE III (A): MODEL SIMULATION RESUlT USING A COMBINATION OF EACH CONSTRAINT

\begin{tabular}{|c|c|c|c|c|c|}
\hline \multirow{2}{*}{$\begin{array}{l}\mathrm{N} \\
\mathrm{o}\end{array}$} & \multirow[t]{2}{*}{ Problem Set } & \multicolumn{2}{|c|}{$\begin{array}{c}\text { Without additional } \\
\text { constraint }\end{array}$} & \multicolumn{2}{|c|}{ [13] and [15] } \\
\hline & & Solution & Time (s) & Solution & Time (s) \\
\hline 1 & O7 & 120.67 & 32 & 120.67 & 8 \\
\hline 2 & FO7 & 23.12 & 27 & 23.12 & 5 \\
\hline 3 & FO8 & 22.39 & 104 & 22.39 & 22 \\
\hline 4 & O9 & 241.06 & 3500 & 260.85 & 187 \\
\hline 5 & V10s & 22899.65 & 6450 & 22899.65 & 1482 \\
\hline 6 & V10a & 21463.06 & 14465 & 21463.06 & 4630 \\
\hline 7 & M11s & 1912.24 & 21220 & 1912.24 & 2480 \\
\hline 8 & M11a & 1504.89 & 86400 & 1504.89 & 5920 \\
\hline
\end{tabular}

TABLE III (B): Model Simulation Result USING A COMBINATION OF EACH CONSTRAINT

\begin{tabular}{|c|c|c|c|c|c|c|c|}
\hline \multirow{2}{*}{$\begin{array}{l}\mathrm{N} \\
\mathrm{o}\end{array}$} & \multirow{2}{*}{$\begin{array}{l}\text { Prob-1 } \\
\text { em Set }\end{array}$} & \multicolumn{2}{|c|}{ [14] } & \multicolumn{2}{|c|}{ [16] } & \multicolumn{2}{|c|}{$[13]-[16]$} \\
\hline & & Solution & $\begin{array}{c}\text { Time } \\
\text { (s) }\end{array}$ & Solution & $\begin{array}{c}\text { Time } \\
\text { (s) }\end{array}$ & Solution & $\begin{array}{c}\text { Time } \\
\text { (s) }\end{array}$ \\
\hline 1 & $\mathrm{O} 7$ & 120.67 & 1 & 120.67 & 8 & 120.67 & 1 \\
\hline 2 & FO7 & 23.79 & 1 & 23.79 & 9 & 23.79 & 1 \\
\hline 3 & FO8 & 22.39 & 3 & 22.39 & 65 & 22.39 & 2 \\
\hline 4 & O9 & 260.85 & 16 & 241.06 & 1040 & 260.92 & 15 \\
\hline 5 & V10s & 22899.65 & 519 & 24336.9 & 5130 & 24336.98 & 43 \\
\hline 6 & V10a & 21463.06 & 206 & 21463.06 & 2565 & 21463.06 & 51 \\
\hline 7 & M11s & 1706.55 & 61 & 1912.24 & 5525 & 1706.55 & 45 \\
\hline 8 & M11a & 1504.89 & 132 & 1504.89 & 7175 & 1504.89 & 81 \\
\hline
\end{tabular}

In the problem set V10s, the simulation result of the constraint combination which gives the optimum value is when using constraints [13], [14], and [15]. When V10s use [16], the result of the solution does not show the optimum value. This can be due to the solution space of this problem, there is no solution that has a resemblance like a mirror image where the same position when confronted with a mirror. This constraint can provide faster computing time by reducing such solution space. 
Overall, all simulated problem sets using additional constraints can provide better computation time than before. The effect that occurs can be the value of the solution becomes not optimum or remain optimum. All computational time gives significant improvement especially when using [14]. And the best computation time and for some problem sets still produce the optimum value, the best combination of constraints used is when using all additional constraints.

[14] becomes the most significant constraint has significant influence in improving the performance of computing time. This is because the [14] provides a reduction to the possibility of a solution space that does not ignore the empty bays that surround the bay are filled. The larger the number of departments owned, the greater the possibility of solution space so that [14] is the best constraint to put into the model. [14] can provide no better value when the number of bays in the simulation results with the optimal value of a department is greater than the number of bays produced on the model using this constraint.

[13] and [15] in general also provide faster computation time than before using the constraints. [13] and [15] provide formula strengthening to the department's lower border. [16] is enough to have a positive effect on the computational time of problem resolution. However, for some problems, [16] becomes no better when the existing problem has special characteristics where it has no greatest material flow value nor a symmetrical solution form.

\section{CONCLUSION}

There are several conclusions that can be drawn from this research:

1) The use of additional constraint function in solving the facility layout problem will affect the computation time and the solution value. The larger the department variables and the complexity of the problem, the greater the computation time it takes.

2) [14] becomes the most significant constraint function in decreasing model computation time. Each addition of constraints provides faster computation time than if not added.

3) The model can be completed with the best computation time when using all additional constraint functions. The value of the resulting solution varies.

4) In some additional constraint function, its use can make the model not find the optimal value because of the influence of characteristics owned by each department. This is due to the complexity and characteristics of each problem and requires the addition of new constraints.

\section{REFERENCES}

[1] The use of additional constraint function on the facility layout problem with the number of departments more than 11 produces solutions within 24 hours running time model with different optimality gap. References

[2] G. Aiello, M. Enea, G. Galante, and L. S., "Multi objective genetic algorithms for unequal area facility layout Problems: A survey," pp. 1998-2003, 1998.

[3] G. C. Armour and S. E. Buffa, "A heuristic algorithm and simulation approach to relative location of facilities," August 2015

[4] R. Bhowmik, "An approach to the facility Layout design optimization," vol. 8, no. 4, pp. 212-220, 1963, 2008.

[5] M. Chang and H. Lin, "A flexible bay structure representation and ant colony system for unequal area facility layout problems," 2012.

[6] M. Chang and H. Lin, "An immunized ant colony system algorithm to solve unequal area facility layout problems using flexible bay structure," pp. 9-18, 2013.

[7] C. D. J. Van, M. W. Carter, and A. Vannelli, "A nonlinear optimization approach for solving facility layout problems," vol. 57, pp. 174-189, 1991.

[8] "International journal of an iterative facility layout algorithm," 2010.

[9] "A review of different approaches to the facility layout problems," 2006.

[10] S. Kulturel-konak and A. Konak, "A new relaxed flexible bay structure representation and particle swarm optimization for the unequal area facility layout problem," Simulation Methodology for Facility Layout Problems, pp. 24-30.

[11] A. Konak, S. Kulturel-konak, B. A. Norman, and A. E. Smith, "A new mixed integer programming formulation for facility layout design using flexible bays," vol. 34, pp. 660-672, 2006.

[12] R. D. Meller, V. Narayanan, and P. H. Vance, "Optimal facility layout design 1," vol. 23, pp. 117-127, 1999.

[13] M. G. Misola and B. B. Navarro, Genetic Algorithm, vol. 7, no. 8, pp. 1691-1696, 2013.

[14] C. E. Nugent, T. E. Vollmann, and J. Ruml, "An experimental comparison of techniques for the assignment of facilities to locations," 2015.

[15] M. Patil and S. Kumanan, "Facility layout optimization using linear and non-linear mixed integer programming," pp. 570-575, 2015.

[16] D. Scholz, A. Petrick, and W. Domschke, "STaTS: A slicing tree and tabu search based heuristic for the unequal area facility layout problem," European Journal of Operational Research, vol. 197, no. 1, pp. 166-178, 2009.

[17] J. C. Smith and Z. C. Ta, "A tutorial guide to mixed-integer programming models and solution techniques," pp. 1-23, 2007.

[18] M. Sharma, R. K. Phanden, and P. Sharma, "Comparative evaluation of facility layout alternatives based on material handling cost," vol. 2, no. 7, pp. 748-751, 2015.

[19] P. Taylor, "Computerized layout design: A branch and bound approach," Unequal-area Facility Layout by Genetic Search Unequal-Area Facility Layout by Genetic Search, 2007.

[20] P. Taylor, S. Kulturel-konak, and A. Konak, "International journal of production unequal area flexible bay facility layout using ant colony optimisation," 2014.

[21] K. Y. Wong, "Expert systems with applications solving facility layout problems using flexible bay structure representation and ant system algorithm," Expert Systems Width Applications, vol. 37, no. 7, pp. $5523-5527,2010$.

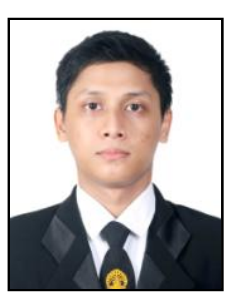

Randa Adi Saputra was born in Jambi, Indonesia on December $24^{\text {th }} 1995$. He got the bachelor of industrial engineering degree in Universitas Indonesia this year. Universitas Indonesia is located in Depok, West Java, Indonesia. 